\title{
ADVANCES IN APPLIED PROBABILITY VOLUME 43 (2011): INDEX General Applied Probability
}

Akgun, O. T., Righter, R. And Wolff, R. Multiple-server system with flexible arrivals ......... Al Hanbali, A., Mandjes, M., Nazarathy, Y. and Whitt, W. The asymptotic variance of

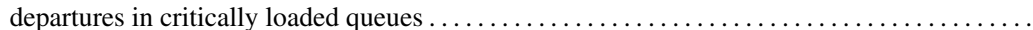

Baccelli, F., BŁaszczyszyn, B. and Haji-Mirsadeghi, M.-O. Optimal paths on the space-time

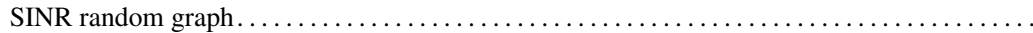

Ball, F. G., KNOCK, E. S. AND O’NeILl, P. D. Threshold behaviour of emerging epidemics featuring

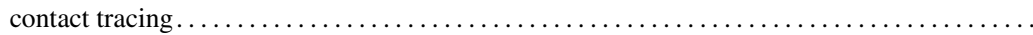

Bansaye, V. see Dombry, C.

BARTROFF, J. AND SAMUEL-CAHN, E. The fighter problem: optimal allocation of a discrete commodity Behme, A. D. Distributional properties of solutions of $\mathrm{d} V_{t}=V_{t-} \mathrm{d} U_{t}+\mathrm{d} L_{t}$ with Lévy noise... BŁaszczyszyn, B. see Baccelli, F.

Cline, D. B. H. Irreducibility and continuity assumptions for positive operators with application to threshold GARCH time series models.

CURIEn, N. AND JoSEPH, A. Partial match queries in two-dimensional quadtrees: a probabilistic

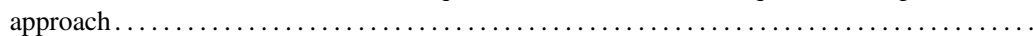

DAI, H. Exact Monte Carlo simulation for fork-join networks $\ldots \ldots \ldots \ldots \ldots \ldots \ldots \ldots \ldots \ldots$

Dassios, A. AND ZhaO, H. A dynamic contagion process . . . . . . . . . . . . . . . . . . .

Dayar, T., Sandmann, W., SpIeler, D. And Wolf, V. Infinite level-dependent QBD processes and

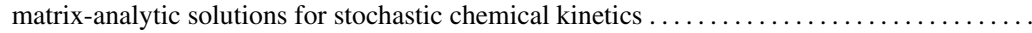

De HaAn, L. AND Zhou, C. Extreme residual dependence for random vectors and processes .....

Demichel, Y., Estrade, A., Kratz, M. and Samorodnitsky, G. How fast can the chord length

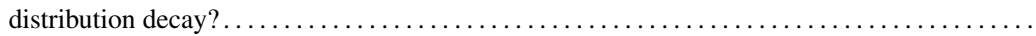

Dia, E. H. A. And Lamberton, D. Connecting discrete and continuous lookback or hindsight options

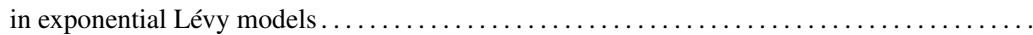

Dombry, C., Mazza, C. And Bansaye, V. Phenotypic diversity and population growth in a fluctuating

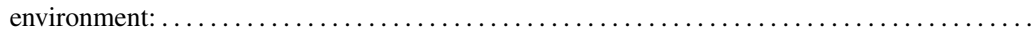

ElmasRy, A. And Mahmoud, H. Analysis of swaps in radix selection $\ldots \ldots \ldots \ldots \ldots \ldots \ldots \ldots$

Estrade, A. see Demichel, Y.

EWALD, C.-O. AND XIAO, Y. Information: price and impact on general welfare and optimal investment. An anticipative stochastic differential game model $\ldots \ldots \ldots \ldots \ldots \ldots \ldots \ldots \ldots \ldots \ldots$

FAller, A. AND RÜSCHENDORF, L. On approximative solutions of optimal stopping problems .... .

FOUCART, C. Distinguished exchangeable coalescents and generalized Fleming-Viot processes with

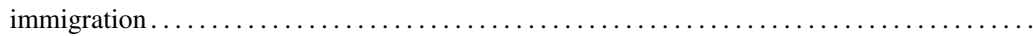

Gallo, S. Chains with unbounded variable length memory: perfect simulation and a visible

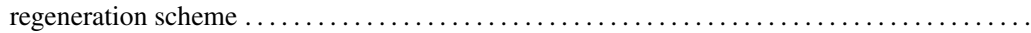

GitTins, J. C. see Qu, S.

Goldstein, L. And Zhang, H. A Berry-Esseen theorem for the lightbulb process .............

Gouet, R., López, F. J. And SAnz, G. Asymptotic normality for the number of records from general

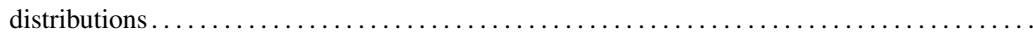

Griffin, P. S. And Maller, R. A. Stability of the exit time for Lévy processes .............. Haji-Mirsadeghi, M.-O. see Baccelli, F.

Holmgren, C. A weakly 1-stable limiting distribution for the number of random records and cuttings in split trees 
HössJer, O. Coalescence theory for a general class of structured populations with fast migration . .

Huillet, T. and Martinez, S. Duality and intertwining for discrete Markov kernels: relations and examples

JARA, M. AND KomorowsKI, T. Limit theorems for some continuous-time random walks.........

$782-813$

JoSEPH, A. see CURIEN, N.

KNOCK, E. S. see BALL, F. G.

KOMOROWSKI, T. see JARA, M.

Kratz, M. see DEMICHEL, Y.

Kvitkovičová, A. and Panaretos, V. M. Asymptotic inference for partially observed branching

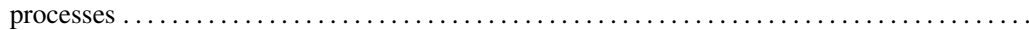

Lamberton, D. see Dia, E. H. A.

LarsSon, M. AND NeŠLEhová, J. Extremal behavior of Archimedean copulas ...

LeE, C. AND WeErasinghe, A. Stationarity and control of a tandem fluid network with fractional

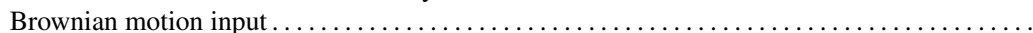

LóPEz, F. J. see GOUET, R.

Mahmoud, H. see ElmasRy, A.

Maller, R. A. see Griffin, P. S.

Mandjes, M. see Al Hanbali, A.

Martinez, S. see Huillet, T.

Mazza, C. see Dombry, C.

Meester, R. and Trapman, P. Bounding basic characteristics of spatial epidemics with a new

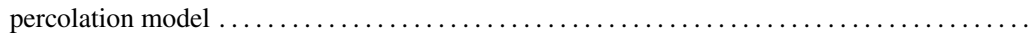

Molchanov, I. And Schmutz, M. Exchangeability-type properties of asset prices .............

Moser, M. And Stelzer, R. Tail behavior of multivariate Lévy-driven mixed moving average processes and supOU stochastic volatility models ...

Nazarathy, Y. see Al Hanbali, A.

NEŠLEHOVÁ, J. see LARSSON, M.

ØKsendal, B., Sulem, A. And Zhang, T. Optimal control of stochastic delay equations and timeadvanced backward stochastic differential equations . . . . . . . . . . . . . . . .

O’NeIll, P. D. see BALl, F. G.

Özbudak, F. see Sezer, A. D.

Panaretos, V. M. see Kvitkovičová, A.

Qu, S. AND GitTins, J. C. A forwards induction approach to candidate drug selection ...........

RICHARD, M. Limit theorems for supercritical age-dependent branching processes with neutral immigration . .

Righter, R. see AKgun, O. T.

RÜSCHENDORF, L. see FALLER, A.

SAMORodnitsky, G. see Demichel, Y.

SAmuel-Cahn, E. see Bartroff, J.

SANDMANn, W. see Dayar, T.

SAnz, G. see Gount, R.

Schmutz, M. see Molchanov, I.

SETAYESHGAR, L. AND WANG, H. Large deviations for a feed-forward network ..............

SEzer, A. D. AND Özbudak, F. Approximation of bounds on mixed-level orthogonal arrays...... .

SonG, J.-S. AND ZIPKIN, P. An approximation for the inverse first passage time problem.........

SPIELER, D. see DAYAR, T.

Stelzer, R. see Moser, M.

Stoev, S. A. see Wang, Y.

Sulem, A. see ØKSEndal, B.

TAMAKI, M. Maximizing the probability of stopping on any of the last $m$ successes in independent Bernoulli trials with random horizon .

Trapman, P. see MeEster, R.

WANG, H. see SETAYEShgar, L.

Wang, Y. And Stoev, S. A. Conditional sampling for spectrally discrete max-stable random fields

Weerasinghe, A. see Lee, C.

Whitt, W. see Al Hanbali, A. 
Wolf, V. see DAYAR, T.

Wolff, R. see Akgun, O. T.

XIaO, Y. see Ewald, C.-O.

$\mathrm{XU}, \mathrm{F}$. The sampling formula and Laplace transform associated with the two-parameter Poisson-

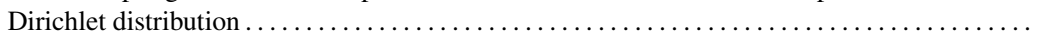

YANG, H. see ZHANG, Z.

Zhang, H. see Goldstein, L.

ZHANG, T. see ØKSENDAL, B.

ZHANG, Z., YANG, H. AND YANG, H. On the absolute ruin in a MAP risk model with debit interest

ZhaO, H. see Dassios, A.

Zhou, C. see De HAAN, L.

ZIPKIN, P. see Song, J.-S. 